\title{
Climate induced Poverty: Impediment to Poverty Alleviation in Developing Countries
}

\author{
Kola O. Odeku \\ Faculty of Management and Law, School of Law, \\ University of Limpopo, South Africa \\ E-mail:kooacademics@gmail.com
}

\author{
Doi:10.5901/mjss.2014.v5n3p672
}

\section{Abstract}

One of the problems facing developing countries of the world is poverty. In some of these countries, there are massive and chronic abject poverty ravaging them and their citizens. The concern is that, the manifestations of the extreme bizarre weather events are causing severe and devastating destruction to human beings and properties; the eco-system is also not spared. Global climate changes are now exacerbating the already worst situation by being one of the major sources of chronic and abject poverty production and severe hunger in the developing countries. The changes are affecting agricultural sector which is the main source of livelihoods for the very poor in the rural remote areas. Undoubtedly, all scientific literatures have confirmed that the poor are the hardest hit considering the fact that majority of them are peasant farmers who cultivates land for food crops, survival and livelihoods. This paper seeks to explain how global climate changes are inducing poverty and becoming more of impediments to poverty alleviation and hunger facing majority of the poorest of the poor in the developing countries. The paper presents an argument for mitigation of climate changes as a short run solution and also impresses on the need for adaptation to climate changes since both concepts are in the forefronts of climate change discourse as solution. The paper concludes that developing countries should strive to continue to promote policy and strategy to mitigate and adapt to climate changes in order to attain sustained economic growth and development.

Keywords: Poverty and hunger, Bizarre weather events, Carbon emissions, Agriculture

\section{Introduction}

Climate change caused by human activities is arguably the most persistent threat to global stability (Adger et al, 2003). The changes in climate are producing devastating and destructive weather events that are impacting negatively on both the living and non-living things (Odeku, 2013). With regard to the living things in the developing countries, erratic changes in the climate are inducing poverty and affecting the livelihood of the developing countries making them to be vulnerable. Describing the socio-economic vulnerability of the people in the developing countries, Adger et al (2003) puts it this way "societal vulnerability to the risks associated with climate change may exacerbate ongoing social and economic challenges, particularly for those parts of societies dependent on resources that are sensitive to changes in climate. Risks are apparent in agriculture, fisheries and many other components that constitute the livelihood of rural populations in developing countries." Consequence upon this, there is need for society to learn how to cope and adapt to the changes in the climate such as warmer temperatures, drier soils, changes in weather extremes, rising sea levels and so on (Adger et al, 2003). The reason for this is that, with the recent opting out of the Kyoto protocol in he last two COP's conferences, the future seems to be bleak for the developing countries that have not been found guilty of contributing huge carbon emissions unlike the developed countries (Antholis and Talbott, 2010). Some of the developed countries that once ratified the Protocol have now pulied out of the obligation to reduce emissions, this presupposes that they will continue to emit with impunity and the developing countries will always be at the receiving ends and will be hardest hit (Bagia, 2010).

\section{Climate-Induced Poverty and Impact on Developing Countries}

Poverty is real in most of the developing countries and it is caused by many factors such as corruption, lack of genuine and visionary leaders, nepotisms, failure to deliver elections promises if it is a democratic country, incessant persistent destructive internal conflicts and wars, natural disasters just to mention a few (Glenn and Gordon, 2002). Manifestation of the impacts of climate change is now exacerbating the already tensed poverty situation and affecting the poor population in most of the developing countries (Nkomo and Nyong, 2006). The impact is creating poverty considering the fact that 
most of the poor in the developing countries rely on agriculture as their means of sustenance and livelihood (Hertel and Rosch, 2010). The impact of the changes in climate is now affecting their livelihoods thereby exposing them to serious threats and sometimes risks of not being able to fend for themselves and family (Wisner, 2004).

\section{Literature Review}

Global warming and climate change are real (King, 2004). The impacts of the changes in the climate are being felt all over the world depending on the geographical location of the country (Richard et al, 2004). Those who are the hardest hit are the developed countries, the world's poorest countries that have contributed least to the emission of greenhouse gases (GHGs) but are most vulnerable to the effects of climate change (Posner and Sunstein, 2007). Geographically, they are also located in some of the most vulnerable regions of the world with low capacities to mitigate or adapt to these changes ( Smit and Wandel, 2006).

Scientific evidence has confirmed that the anthropogenic drive is getting stronger by the day with huge environmental consequences. Scientific evidence has also confirmed the influence of regional temperature that is bringing about changes on many physical and biological systems (Thompson, 2010). Typical examples are the aggressive and destructive torrential rainfalls being witnessed in developing countries like Bangladesh, India and Mozambique resulting into huge floods that eventually destroyed people, properties and the ecosystems. The developed countries are not spared, there have been physical manifestation of impact of climate change which had increased the size of glacial lakes in the "Arctic and Antarctic regions owing to the melting of glaciers; hydrological systems have been affected; and there have been changes in terrestrial ecosystems, such as poleward and upward shifts in plant and animal ranges (Chambwera and Stage 2010:5)."

Explaining the dynamics of changes in the climate brought about as a result of carbon emissions, Chambwera and Stage (2010:6) indicates that "Anthropogenic carbon emissions have been an important driver of these temperature changes. Between 1970 and 2004, greenhouse gas (GHG) emissions caused by human activities increased by 70 per cent (IPCC, 007). Emissions of carbon dioxide (CO2), the most important GHG, grew by about 80 per cent between 1970 and 2004 and by 28 per cent between 1989 and 2004. The IPCC Fourth Assessment (2007) claims that it is 90-99 per cent likely that the rise in global temperature seen since the mid-19th century has been caused by human activities. There have also been advances in the knowledge pertaining to the impacts of climate change in different sectors and geographical zones. The key sectors for which general impacts are expected are:

- freshwater resources

- ecosystems

- food, fibre and forest areas

- coastal systems and low-lying areas

- health

- industry, settlement and society."

It is apparent from the above quote that human activities that seek to use fossil fuels that emits carbon dioxide to the atmosphere causing global climate changes are the main driver of global warming and climate change (Seinfeld and Pandis, 2012). Pursuant to this, other sectors of the human endeavours are being affected, particularly those resources that are meant to be used to produce and provide basic socio-economic goods and services to the people in order to improve their standard of living and health (AMCEN, 2011).

The concern is that literature on agricultural sector has confirmed that the sector is "vulnerable to climate changes physically and economically and that agricultural production and supply are being affected thereby altering the structure of the livelihoods and income of the farmers (Gbetibouo and Hassan, 2005). More importantly, the risk of the impact of climate change is higher in agricultural sector which is the main source of survival and livelihoods of the rural population in developing countries (McMichael et al, 2007). Consequently, distortion and destruction to the freshwater resources, ecosystems, food, fibre and forest areas, coastal systems and low-lying areas and health as a result of the impact of global climate change (Schneider et al, 2001) will definitely affect basic socioeconomic goods and services and the expected results are chronic poverty and hunger because the vulnerable poor in the rural areas who rely on these resources to produce their means of livelihood are being devastatingly affected (Ribot, 2010). Undoubtedly, climate change is a threat to all aspects of human endeavours and its impact seems to be creating huge gap towards the attainment of regional and international developmental goals of many developmental programmes such as the Millennium Development (Chambwera and Stage, 2010). As part of alleviation of poverty and hunger, it is important to identify the area of agricultural need (Dixon and Gulliver, 2001). 


\section{Eradicating Climate-Induced Hunger and Poverty}

In most of the developing countries of the world, most poor people live in rural areas and majority of them are peasant farmers who depend largely on agriculture for their food and livelihood (Dixon and Gulliver, 2001). These small scale farmers engage in agricultural activities which produce much of the needed food required by the people (Morton, 2007). Against this backdrop of productive activities, it is expected that their efforts will translate to affluence and riches, however, the contrary is the case as most of the small scale farmers in the rural areas in the developing countries are poorer than the rest of the population. They are also more vulnerable and less food secure than the urban poor (Dixon and Gulliver, 2001). In order to eradicate hunger and poverty, there is need to channel efforts toward the creation of dynamic and sustainable rural communities founded upon progressive and prosperous farming that will be resistant and resilient to erratic weather events (Dixon and Gulliver, 2001).

There is a very strong tie between poverty and hunger (Sen, 2006). Both poverty and hunger have similar characteristics and outcomes (Hill et al, 2007). They present situations of lack, vulnerability, destitute, hopelessness, and disgruntlement and highly disillusioned. Articulating how poverty and hunger are closely intertwined, Dixon et al. (2001:5) asserts that "Hunger and poverty are closely related. While the lack of sufficient income to purchase food is clearly a major factor causing household food insecurity, hunger itself contributes to poverty by lowering labour productivity, reducing resistance to disease and repressing educational achievements." Against this backdrop and in order to alleviate poverty and hunger, farming therefore becomes a major factor in eradicating poverty. In support of this assertion, Rigg (2005:180) opines that "the assumption sometimes explicitly stated but more often implicit, is that the solution to global poverty lies in the invigoration of farming and the redistribution of land. It is, in short, at the nexus between land and agricultural productivity that a resolution to rural poverty in the Global South-and therefore to global poverty-is to be found."( Rigg, 2006).

The expertise of the competent skilled agriculturists is needed in this regard. A blend of indigenous knowledge of farming and modern day technological farming should be promoted and encouraged. In the context of climate change related poverty and hunger, there is need for aggressive adaptation strategies in the developing countries. Research works have shown that there have been a lot of scholarly writings and implementations on mitigating the impact of climate changes that have been successfully reported and demonstrated in developing countries, but few has been done on adaptation. While activities surrounding mitigation should continue, adaptation should also be given the attention it deserves. Adaptation is very important in that it allows developing countries to be resilient to the negative impacts of climate change (Mendelsohn and Dinar, 1999). This implies that even if the impacts manifest, it will have little or no devastating or destructive tendencies and effects on the agricultural products and farms. The benefit of this is that the projected food production will be realisable even if the bizarre event occurs. Furthermore, there will be no threat to food security and production will enhance income, alleviate poverty and hunger.

To actualise this, there is need for transition to technology that will make this possible in both short and long run. This will require enlisting the expertise of those who have the where withal and required skills and manpower to drive the adaptation agenda.

\section{Mainstreaming Adaptation to Climate Change}

While various strategies have been deployed as drivers to cope with the changing climate, "there is also considerable interest in identifying practical strategies that could help reduce or ameliorate anticipated negative effects of climate change."(Mawdsley et al., 2009). In the climate change discourse "these approaches are commonly termed as "adaptation strategies." (Mawdsley et al 2009).

Incorporation of adaptation strategies is significantly important now especially if the developing countries would want to continue with sustainable economic growth and developmental paths that will preserve the ecosystem, improve and increase food production in order to alleviate poverty and hunger (Deininger and Byerlee, 2011). In Bangladesh, a country known for its chronic floods with devastating consequences is highly vulnerable to coastal flooding and the vulnerability is exacerbated by the impact of climate change due to a combination of factors (Agrawala et al, 2003). According to Agrawala et al (2003:34-36), "Bangladesh already employs coastal embankment towards management of coastal flooding, particularly when it is caused by high tides and storm surges. However, inadequate drainage infrastructure along an embankment can be counter-productive, and could interact with several aspects of climate changes to produce a cascade of adverse consequences that could in fact enhance the vulnerability of the coastal areas in Bangladesh." 
To find solution to this dreadful flooding in order to preserve livelihoods, households and their well-being, sustainable coastal and freshwater developments, the adaptation strategies employed in Bangladesh were "to build or maintain appropriate drainage infrastructure along coastal embankments, installed flow regulators in the design of existing embankments...complemented by an assessment of the need for refurbishing existing regulators, followed by their periodic monitoring....another family of physical adaptation measures could revolve around enhancing the drainage and/or conveyance capacity of the coastal rivers. This could involve excavation/dredging of silting rivers to unclog their waterways. Controlled flooding to enhance sedimentation and thereby raise the floodplain further upstream is another adaptation measure that could enhance drainage by increasing the flow gradient. This measure has already been tested under the Khulna-Jessore Drainage Rehabilitation Project ...Raising of the floodplain upstream helped drain the excess water, which in turn reduced flood vulnerability. Post project appraisals have concluded that this 'tidal basin 'concept to be acceptable to the local population....Another adaptation measure would involve the use of lifting pumps to take out excessive water from the flood affected areas may be considered as a physical adaptation. Since this involves high costs, it is considered only to save high value properties, infrastructure, urban centres and industrial zones.... Pumping option as an adaptation may, therefore, be considered to solve certain specific problems (such as salinization of potable water reservoirs) that are expected to occur under climate change... the ongoing trend towards more effective disaster early warning and response in Bangladesh is also a viable adaptation strategy for flooding that might result from enhanced cyclone intensity that is projected under climate change. The directives given by the Standing Order on Disasters.... in particular may be considered as elements of institutional adaptation. Continuous monitoring of the formation of cyclones in the Bay of Bengal involving satellite-based technology; monitoring the gradual development and track of imminent cyclone; issuance of cyclone warning well ahead of time for the people to take precautionary measures; evacuation from homesteads and relocation in multi-purpose cyclone shelters and concrete buildings - all may be considered as highly useful and proven adaptation strategies. Already such measures have allowed thousands of coastal people to successfully avoid loss of lives during two high intensity cyclonic events: one occurring in 1994 and the other in 1997 (Agrawala et al. 2003:34-36)."

Virtually all the scientific evidences have confirmed that the impacts of climate changes will strongly affect the African continent and will be one of the challenging issues for future development, particularly in the drier regions (Mertz et al, 2009). In the Sahel region of West Africa, the impacts of climate changes on agriculture and food are also apparent (Tschakert, 2007). There have been huge impact factors from wind and occasional excesses of rainfall on major sources of livelihood such as livestocks and crops. (Urama and Ozor, 2010). Coping and adaptation to climate changes have always been based on traditional indigenous knowledge through crop diversification, mobility, livelihood diversification and migration (Mertz et al, 2009). Mertz et al (2009:804-805) assert that rural communities in the Sahelian zone of West Africa have always managed their resources and livelihoods in the face of challenging environmental and socioeconomic conditions.... They have to a large extent been able to develop their livelihood strategies in a way which enable them to constantly cope with and adapt to an erratic climate, severe pest attacks, changing policies at local, national, and global levels, and so on."

While the indigenous and traditional coping and adaptation strategies are considered as part of the solution to the changing climate, in view of the increase in population and the demand for food and other agricultural products, mechanised farming which involves the use of modern technology becomes more important in a bid to have huge output of food production that will meet the needs of the growing population (Xianl et al, 2011).

South Africa is also vulnerable to the negative effects of climate change (Erasmus et al, 2011). Against this backdrop, the government has put in place numerous mitigation and adaptation strategies. However, the concern is that implementation is not at pace with the devastating consequences of climate change. Pursuant to this, with regard to poverty and hunger, and as part of coping and adaptation strategies, Gbetibouo and Hassan (2005) pointed out that "there is a need to identify effective risk-pooling mechanisms. Adaptation can be addressed in a variety of ways. First and foremost is the greatest challenge of educating farmers about the happenings of climate change and its impacts. Hence more effective extension programs are needed to increase farmers' awareness of climate change. Certainly, prevention of losses can occur through more effective farm planning. Crop insurance, diversified economic bases of regions dependent on farming, and improved monitoring and forecasts of weather will also increase resilience to cope with future changes." (Gbetibouo and Hassan, 2008).

Although climate change is a global problem, the need for adaptation is significant in most of the developing countries because of their vulnerability as they are very prone to various climatic disasters (Adger et al. 2003). Undoubtedly, human-induced climate change is caused by human activities and the solution ultimately lies on humans to mitigate the impact (Kasperson and Kasperson, 2001). However, mitigation seems to be very slow and seems not to be 
producing the desired result hence the need for adaptation option in areas that are vulnerable to the impact of climate change (Thornton, 2009). Adaptation intervention becomes more pressing and it is needed urgently because the manifestations and the impacts of global warming and climate change are putting the gains made so far at risk (Pindyck, 2007).

One of the potent adaptation strategies that will address the issues surrounding effects of global climate change is the genuine increase in capacity to manage extreme weather events ( Lal et al, 2002). Capacity building will lead to a long-term sustainable development planning in developing countries (Adger et al, 2005). Hence the need for "lending agencies and donors to reform their investment policies in developing countries to focus more on capacity building instead of just investing in recovery operations and infrastructure development." (Mirza, 2003).

\section{Conclusion}

The reality is that, the impacts of climate change will continue and will affect a whole range of human end ecosystems. Food is very important for both human and animal existence. All efforts should be geared toward adaptation in order to ensure adequate and sustainable food production and security. The impediments were caused by human activities; it is believed that through viable and genuine interventions by all stake holders, these impediments can be contained. Towards this end, carbon emissions causing global climate should be combated from all fronts.

\section{Recommendations}

Developing countries are experiencing various socio-economic problems and global climate change is exacerbating them. Most of these countries rely on agriculture and food production as sources of livelihood and foreign exchange earnings through export of agricultural products. For this to continue, adaptive measures need to be implemented because if these are not done, it might trigger hardships, severe hunger and so on. It is imperative for the developed countries to reduce their appetite for the use of fossil fuels causing global climate change and affecting hugely, the developing countries' livelihoods.

\section{Refernces}

Adger WN, Arnell NW, Tompkins EL 2005. Successful adaptation to climate change across scales, Global Environmental Change, 15(2): 77-86.

Adger WN, Huq S, Brown K, Conway D, Hulme M 2003. Adaptation to climate change in the developing world, Progress in Development Studies, 3:179-175.

Agrawala S, Ota T, Ahmed AU, Smith J, van Aalst M 2003. From http://static.weadapt.org/placemarks/files/226/21055658.pdf. (Retrieved February 10, 2014).

AMCEN, 2011: African Ministerial Council on the Environment. Addressing Climate Change Challenges in Africa; A Practical Guide Towards Sustainable Development. From http://www.unep.org/roa/amcen/docs/publications/guidebook_CLimateChange.pdf. (Retrieved February 8, 2014).

Antholis W, Talbott S 2010. Fast forward: Ethics and politics in the age of global warming, Brooking Institution Press, Washington, USA.

Assan JK, Caminade C, Obeng F 2009. Environmental variability and vulnerable livelihoods: Minimising risks and optimising opportunities for poverty alleviation, Journal of International Development, 21(3): 403-418.

Bagia T 2010. Passion For Our Planet: Barack Obama and the Vision For Alternative Energy Sources In an Interdependent World, Author House Publishers, Bloomington, Indiana, USA.

Chambwera M, Stage J 2010. Climate change adaptation in developing countries: issues and perspectives for economic analysis, International Institute for Environment and Development Publication, London, UK.

DA King 2004. Climate change science: adapt, mitigate, or ignore? From http://www.heatisonline.org/contentserver/objecthandlers lindex.cfm?id=4566\&method=full. (Retrieved March 1, 2014).

Deininger KW, Byerlee D 2011. Rising global interest in farmland: can it yield sustainable and equitable benefits? The World bank, Washington, USA.

Dixon JA, Gulliver A 2001. Farming systems and poverty: improving farmers' livelihoods in a changing world, FAO and World Bank Publication, Washington, USA.

Erasmus BFN, Van Jaarsveld AS, Chown SL, Kshatriya M, Wessels KJ 2011. Vulnerability of South African animal taxa to climate change, Journal of Soil and Water Conservation, 66(4):276-285.

Gbetibouo GA, Hassan RM 200. Measuring the economic impact of climate change on major South African field crops: a Ricardian approach, Global and Planetary Change, 47(2-4):43-152.

Gbetibouo GA, Hassan RM 2005. Measuring the economic impact of climate change on major South African field crops: a Ricardian 
approach, Global and Planetary Change, 47(2-4):143-152.

Glenn JC, Gordon TJ 2002. Creating a better world: 15 global challenges, "Creating a better world: 15 global challenges, Foresight, $4(5): 15-37$

Hertel TW, Rosch SD 2010. Climate change, agriculture, and poverty, Applied Economic Perspectives and Policy, 32 (3): $355-385$.

Hill RV, Smith LC, Frankenberger T, Gulati K 2007. The world's most deprived: Characteristics and causes of extreme poverty and hunger, International Food Policy Research Institute Publication, Washington, USA.

Kasperson RE, Kasperson JX 2001. Climate change, vulnerability, and social justice. From http://stc.umsl.edu/essj/unit4/climate \%20change\%20risk.pdf. (Retrieved January 19, 2014).

Lal R, Delgado JA, Groffman PM, Millar N, Dell C, Rotz A 2002. Management to mitigate and adapt to climate change, Global Change Biology, 8(7): 679-693.

Mawdsley JR, O'Malley R, Ojima DS 2009. A Review of Climate-Change Adaptation Strategies for Wildlife Management and Biodiversity Conservation, Conservation Biology, 23(5):1080-1089.

McMichael AJ, Powles JW, Butler CD, Uauy R 2007. Food, livestock production, energy, climate change, and health, The Lancet, 370(9594):1253-1263.

Mendelsohn R, Dinar A 1999. Climate Change, Agriculture, and Developing Countries: Does Adaptation Matter? World Bank Research Observer, 14 (2): 277-293.

Mertz O, Mbow C, Reenberg A, Diouf A 2009. Farmers' Perceptions of Climate Change and Agricultural Adaptation Strategies in Rural Sahel, Environmental Management, 43:804-816.

Mirza MQM 2003. Climate change and extreme weather events: can developing countries adapt? Climate Policy, 3(3): $233-248$.

Morton JM 2007. The impact of climate change on smallholder and subsistence agriculture. From http://www.pnas.org/content /104/50/19680.short. (Retrieved February 19, 2014).

Nkomo JC, Nyong AO 2006. The impacts of climate change in Africa. From http://www.xn--deutscher-fluglrmdienst97b.de/Presse/PMitt/2006/061030c8.pdf. (Retrieved January 9, 2014).

Odeku KO 2013. Shifting towards Sustainable Events by Using Alternative Energy and Energy-Efficient Devices, Mediterranean Journal of Social Sciences, 4(14):835-845.

Pindyck RS 2007. Uncertainty in environmental economics, Review of environmental economics Policy, 1(1): 45-65.

Posner EA, Sunstein CR 2007. Climate Change Justice, Georgia Law review, 96:1565-1573.

Ribot J 2010. Vulnerability does not fall from the sky: toward multiscale, pro-poor climate policy, The World bank Publication, Washington, USA.

Richard S.J Tol RSJ, Downing TE, Kuik OJ, Smith JB 2004. Distributional aspects of climate change impacts, Global Environmental Change, 14(3): 259-272.

Rigg R 2006. Land, farming, livelihoods, and poverty: Rethinking the links in the Rural South, World Development, 34(1):180-202.

Schneider S, Sarukhan J, Adejuwon j, Azar C 2001. Overview of impacts, adaptation, and vulnerability to climate change, Press Syndicate of the University of Cambridge, Cambridge, UK.

Seinfeld JH, Pandis SN 2012. Atmospheric chemistry and physics: from air pollution to climate change, John Wiley \& Sons publishers, New Jersey, USA.

Sen A 2006. Conceptualizing and measuring poverty, Stanford University Press, Stanford, California, USA.

Smit B, Wandel J 2006. Adaptation, adaptive capacity and vulnerability, Global Environmental Change, 16(3): 282-292.

Thompson LG 2010. Climate change: The evidence and our options, The Behavior Analysis, 33(2): 153-170.

Thornton PK, van de Steeg J, Notenbaert A, Herrero M 2009. The impacts of climate change on livestock and livestock systems in developing countries: A review of what we know and what we need to know, Agricultural Systems, 101(3):113-127.

Tschakert P 2007. Views from the vulnerable: Understanding climatic and other stressors in the Sahel, Global Environmental Change, 17(3-4):381-396.

Urama KC, Ozor N 2010. Impacts of climate change on water resources in Africa: the role of adaptation . From http://www.ourplanet.com/climate-adaptation/Urama_Ozorv.pdf. (Retrieved February 24, 2014).

Wisner B 2004. At risk: natural hazards, people's vulnerability and disasters, Routledge, London, UK.

Xianli Z, Clements R, Haggar J, Quezada A, Torres J 2011. Technologies for Climate Change Adaptation - Agriculture Sector. From. http://forskningsbasen.deff.dk/Share.external?sp=Seb84fde4-6a26-45b3-a23f-b2a63c9fc860\&sp=Sdtu. (Retrieved March 2, 2014). 